\title{
Nocturnal light pollution and clinical signs of ovulation disorders
}

\author{
Marie Garmier-Billard ${ }^{1}$, Joy DeFelice ${ }^{2}$, Françoise Soler ${ }^{3}$, Jean Iwaz ${ }^{1,4,5,6}$ and René Ecochard ${ }^{1,4,5,6 *}$ \\ ${ }^{1}$ Hospices Civils de Lyon, Pôle Santé Publique, Service de Biostatistique-Bioinformatique, Lyon, France \\ ${ }^{2}$ Sacred Heart Medical Center, Natural Family Planning Program, Spokane, Washington USA \\ ${ }^{3}$ ACODIPLAN (Association for Coordination and Divulgation of Natural Family Planning), Barcelona, Spain \\ ${ }^{4}$ Université de Lyon, Lyon, France \\ ${ }^{5}$ Université Lyon 1, Villeurbanne, France \\ ${ }^{6}$ CNRS, UMR 5558, Laboratoire de Biométrie et Biologie Évolutive, Équipe Biostatistique-Santé, F-69100, Villeurbanne, France
}

\begin{abstract}
Objective: Assess quantitatively the impact of nocturnal light pollution on the menstrual cycle.

Design: Cross-sectional observational study.

Setting: Single French institute from November 2017 to March 2018.

Participants: Nineteen ostensibly healthy menstruating women aged 19 to 45 , inclusive

Intervention(s): None

Main outcome measures: Assessment of nocturnal light pollution (questionnaire and lux meter) and 22 clinical signs of ovulation disorder. Wilcoxon tests were used to quantify the abilities of nocturnal light pollution factors to predict clinical signs of ovulation disorders.

Results: Nearly half of the 94 daily observations made by questionnaire and measurements made by lux meter indicated light pollution due to light flooding into the bedroom from indoor or outdoor sources. Nearly more than half of the 56 menstrual cycles presented at least mild abnormalities. The data showed that some clinical signs of ovulation disorders may be significantly predicted by factors of light pollution but a lack of power prevented reaching Bonferroni criterion.

Conclusions: The indications of negative impact of dim light at night on some menstrual cycle characteristics call for a randomized study to quantify improvements of menstrual cycle characteristics brought by suppressing nocturnal light pollution. This will pave the way for new therapeutic perspectives for some difficult cases of ovulation disorders.
\end{abstract}

\section{Introduction}

In recent decades, infertility has become a source of concern for many couples; thus, an increasingly frequent reason for consultation. Lifestyle changes would be the main reason for the current increase in infertility [1]. Indeed, one of the major factors that affect women's fertility is delaying the age of motherhood that leads to childbearing desire at ages with low ovarian reserve and altered oocyte quality [2]. Meanwhile, it has been recently shown that women living in polluted areas are at higher risks of menstrual cycle abnormalities [3,4]. The pollution factors responsible for these abnormalities remain unknown. Actually, heavily polluted areas present several types of pollution whose effects could not be disentangled by epidemiological studies [5]: air/ water/food pollution, environmental circadian disruption [6], but also light pollution [7]. In fact, most polluted areas are urban or peri-urban areas with strong night lighting.

Exposure to light [8-10], especially at night [11], or during sleep [12], influences melatonin secretion. Light pollution during the night and shift work schedules may reduce melatonin synthesis and impair homeostasis. Several studies have shown that light can inhibit melatonin secretion in a dose-dependent way according to the light spectrum [13].
Indirect observations have suggested a possible impact of light pollution on fertility. The link between night work and fertility as well as the link between night work and gynecological pathology [14] seem to be well established now. Women who work at night are more at risk of irregular cycles [15-17]. Shift workers who experience sleep disturbances and exposure to light at night are at increased risk of specific alterations of the menstrual cycle [18]. However, it is difficult to distinguish the impact of night work from that of exposure to light at night or during sleep.

The link between light and fertility is well known in animals [19]. It is so important that it is used on a large scale in livestock farming to increase production; for example, egg laying in poultry. In women, the link between light and fertility is only suspected; firm evidence is still

${ }^{*}$ Correspondence to: René Ecochard, Service de Biostatistique-Bioinformatique 162 avenue Lacassagne F-69424-Lyon Cedex 03-France, Tel: +33472115153, E-mail: rene.ecochard@chu-lyon.fr

Key words: light pollution, dim light, menstrual cycle, ovulation disorder

Received: April 19, 2019; Accepted: May 30, 2019; Published: June 03, 2019 
lacking. Admitting that exposure to light alters melatonin secretion, would light perceived during sleep disturb the menstrual cycle and, ultimately, affect fertility?

A preliminary unpublished study conducted by one of the authors (JD) in the USA has identified a number of light sources in the bedroom seemingly related to abnormalities of the menstrual cycle; specifically, ovulation disorders. This study showed that decreasing nocturnal light resulted in a significant reduction in abnormal parameters in six cycles and in the occurrence of a number of pregnancies in previously infertile women having had these cycles $[20,21]$. The present study was conducted to assess quantitatively the impact of nocturnal light pollution (as assessed by a questionnaire and measured by a lux meter) on the menstrual cycle.

\section{Material and methods}

This cross-sectional observational study was carried out in France from November 2017 to March 2018. Caucasian women were recruited from a French institute for the study of the menstrual cycle (CYCLEFEMININ institute).

\section{Inclusion and exclusion criteria}

The inclusion criteria considered ostensibly healthy menstruating women, aged 19 to 45 inclusive, with experience in natural family planning methods; mainly, basal body temperature (BBT) and signs of cervical mucus [22].

The following potential participants were excluded: women on programs to stimulate hormonal responses for infertility reasons; women on oral, transdermal, or other hormonal contraceptive method; and women on hormonal replacement therapy.

The study retained finally 26 participant women. Each of them gave her written informed consent and the study procedures were carried out in accordance with the Ethical Standards for Human Experimentation established by the Declaration of Helsinki.

\section{Menstrual cycle data}

The participants had to record BBT and some features of cervical mucus on a menstrual cycle chart. The BBT was the wakeup temperature taken before any activity and recorded on a special individual chart together with the date, the cycle day, and any condition likely to affect temperature (e.g., stress, illness, insomnia, sickness, etc.). Cervical mucus was collected at the vulva and assessed two to three times daily to record the sensation (dry, moist, wet, slippery) and the consistency (tacky, creamy, stretchy) on the BBT chart. A stretchy or lubricative mucus discharge was called the peak-type mucus.

\section{Light exposure data}

Exposure to light during sleep was assessed by questionnaire and measured by lux meter.

In the questionnaire, each participant was asked to identify accurately the sources of light pollution in her bedroom: 1) sources of artificial light, 2) factors likely to increase bedroom light; 3) sources of indoor artificial light reflected into the bedroom; and, 4) sources of outdoor artificial or natural light reflected into the bedroom. This had to be carried out over five successive nights. The average number of light sources in each of the above four categories was kept for the statistical analysis.

Light measurements used HI97500 portable digital lux meter (HANNA Instruments, Tanneries, France). According to the manufacturer, this device is able to measure low light intensities, down to 0.01 lux. For illustration and further result interpretation, it should be mentioned that the naked human eye is able to perceive light intensities in the order of 0.01 lux. A lux meter was lent to each participant who had to measure her bedroom light over five successive nights. Here, too, the average of the five measurements was kept for the statistical analysis.

The current study presents no time measurements, no timed exposures, and no exposures tied to the phases of the cycle because it was considered: i) that everyday exposure to light during night was rather uniform or regular during the low-light season (NovemberMarch); and, ii) the menstrual cycle as a single entity; any disturbance of follicle development has potential consequences on other phases of the cycle.

\section{Outcome criteria}

A second questionnaire was used to describe the three previous menstrual cycle charts. The signs for ovulation disorders have been previously defined by author JD according to Creighton model [23] and clinical experience. In this questionnaire, 22 questions about the menstrual cycles focused on: 1) the menstrual flow (duration, intensity, and color of bleeding; presence of prolonged spotting); 2) the latency period (from first day of menstruation to the day before mucus flow reaches the vulva); 3 ) the flow of cervical mucus to the vulva (different types of mucus, associated sensation); 4) the thermal plateau; 5) the post-peak phase (duration, presence of cervical mucus, and spotting); 6) the length of the cycle.

The study collected the frequencies of various signs for ovulation disorder for statistical analysis purposes.

\section{Statistical analysis}

The assessment of the ability of nocturnal light pollution to predict clinical signs of ovulation disorders used Wilcoxon tests. Each of the four categories of light pollution sources and lux meter measurement was used as predictor and each of the 22 clinical signs of ovulation disorder used as predicted event. One hundred and ten, (5x22) Wilcoxon tests were performed and boxplots used to examine the relationships between light pollution and signs of ovulation disorder.

The prediction of clinical signs of ovulation disorder by nocturnal light pollution was considered as statistically significant when a Wilcoxon test p-value was below 0.05 . Bonferroni method was used to correct for multiple comparisons: as the analysis tested 110 hypotheses with a desired $\alpha=0.05$, Bonferroni correction requires testing each individual hypothesis at the significance level of $\alpha / n=0.05 / 110=0.00045$.

All statistical analyses were carried out with $\mathrm{R}$ software, version 3.5.3.

\section{Results}

Among the 26 participants, one woman had to quit the study because of pregnancy. In addition, the data of six participants were excluded from the analysis because of insufficient data on the menstrual cycles (5 cases) or on exposure to light at night. Thus, the analysis concerned complete data on 19 participants and 56 cycles: 3 cycles in 18 women and 2 cycles in one woman. Figure 1 shows the process of participant selection.

\section{Description of the menstrual cycles}

Table 1 shows the frequency of observed signs for ovulation disorders in descending order. 


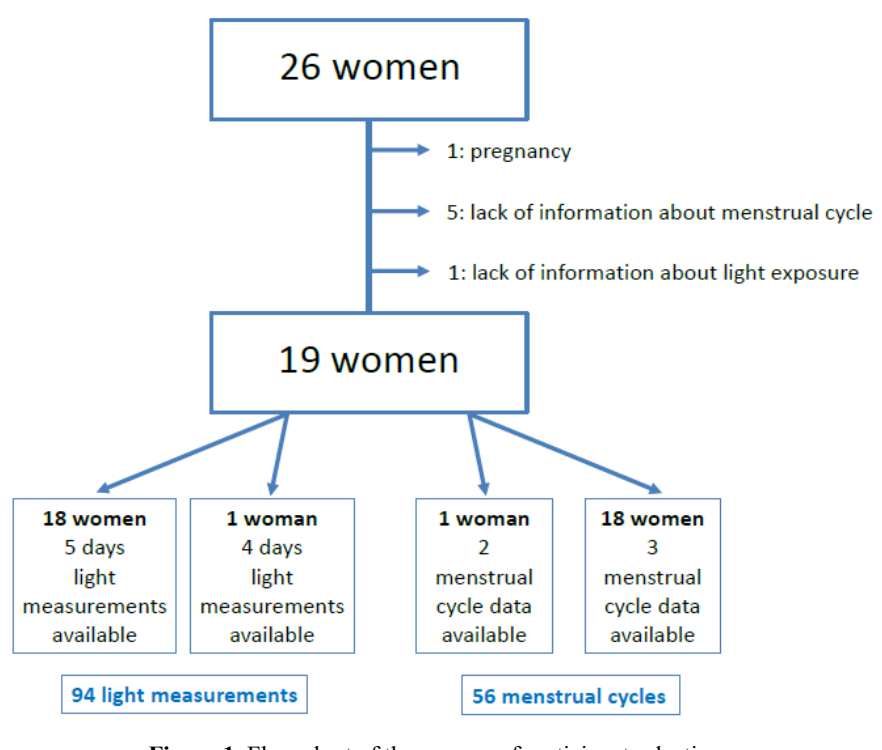

Figure 1. Flow chart of the process of participant selection

Table 1. Frequency of menstrual cycle signs in 56 cycles

\begin{tabular}{|l|c|c|}
\hline Signs & Frequency & Percentage \\
\hline Seven days or more of mucus discharge & 27 & 48.2 \\
\hline A lot of mucus felt or seen during the luteal phase & 27 & 48.2 \\
\hline Less than 3 days of peak-type mucus & 22 & 39.3 \\
\hline Short luteal phase (less than 10 days) & 16 & 28.6 \\
\hline Delayed BBT shift (19 days or more) & 16 & 28.6 \\
\hline Menstrual flow - Brown/blackish spotting & 14 & 25.0 \\
\hline Early cervical mucus at end of menstrual flow & 13 & 23.2 \\
\hline Menstrual flow - Mostly heavy flow & 13 & 23.2 \\
\hline Minimal mucus, no peak-type mucus & 12 & 21.4 \\
\hline No sustained BBT shift or weak shift & 11 & 19.6 \\
\hline No dry days after menses & 11 & 19.6 \\
\hline Menstrual flow for 7 days or more & 10 & 17.9 \\
\hline Menstrual flow - Prolonged spotting after flow ends & 9 & 16.1 \\
\hline Continuous dampness or wetness over the whole cycle & 8 & 14.3 \\
\hline Two days or more of spotting during mucus & 5 & 8.9 \\
\hline BBT shift - Erratic postovulatory readings & 5 & 8.9 \\
\hline More than two days of pre-period spotting & 3 & 5.4 \\
\hline Fertile-type mucus present after temperature rise & 3 & 5.4 \\
\hline Bleeding/spotting for 5-6 days during the preovulatory phase & 2 & 3.6 \\
\hline Cycle length of 35 days or more & 2 & 3.6 \\
\hline Continuous fertile-type mucus over the whole cycle & 1 & 1.8 \\
\hline $\begin{array}{l}\text { Menstrual flow - Prolonged absence of menstrual flow (2-3.5 } \\
\text { months) }\end{array}$ & 1 & 1.8 \\
\hline $\begin{array}{l}\text { Basal body temperature shift - Temperature readings become } \\
\text { weak from mid luteal phase to end of cycle }\end{array}$ & 1 & 1.8 \\
\hline BBT: Basl body temper & & \\
\hline
\end{tabular}

BBT: Basal body temperature

Seven days or more of mucus discharge and presence of mucus during the luteal phase were the most frequent characteristics observed in nearly half of the menstrual cycles. Less than three days of peak-type mucus was also frequently mentioned and atypical lengths of either the preovulatory phase or the luteal phase were observed in nearly one third of the menstrual cycles.

Some abnormality in menstrual bleedings was also rather frequent. The other signs of ovulation disorders were less frequent in the present dataset.

\section{Description of nocturnal light pollution}

Table 2 lists the main sources of indoor and outdoor artificial or natural light pollution of the bedroom. Among the main light sources, the presence of a digital alarm clock was cited in $40 \%$ of studied nights and the presence of street light flooding into the bedroom was found in $31 \%$ of studied nights.

At least one artificial light source was present in the bedroom in 57 out of 94 nights $(60.6 \%)$. At least one factor influencing light was reported in 49 nights (52.1\%). At least one indoor artificial light source reflecting into the bedroom was reported in 35 nights (37.2\%). At least one outdoor light source reflecting into the bedroom was reported in 67 nights (71.2\%).

Sixty-six out of 94 light intensity measurements with lux meter (70.2\%) had non-zero values. These values were $0.01 \mathrm{~lx}, 0.02 \mathrm{~lx}, 0.03 \mathrm{~lx}$, and $>0.03 \mathrm{~lx}$ in, respectively, 18, 13,14, and 21 measurements.

\section{Prediction of clinical signs of ovulation disorders by light pollution}

Table 3 provides the exact p-values of Wilcoxon tests. Each p-value quantifies the level of evidence of each relationship between light

Table 2. Sources of light pollution in the bedroom observed by 19 women over 94 nights

\begin{tabular}{|c|c|c|}
\hline Sources of light pollution & Frequency & Percentage \\
\hline \multicolumn{3}{|l|}{ Sources of artificial light in the bedroom } \\
\hline Digital alarm clock & 38 & 40 \\
\hline Bright light switch & 15 & 16 \\
\hline Bright alarm clock & 15 & 16 \\
\hline Standby lights (TV, Wi-Fi, etc.) & 10 & 11 \\
\hline Light from a heating device & 10 & 11 \\
\hline Clock projecting time on ceiling & 7 & 7 \\
\hline Phone light & 6 & 6 \\
\hline Reading light & 5 & 5 \\
\hline Laptop light & 5 & 5 \\
\hline \multicolumn{3}{|l|}{ Factors that increase bedroom light } \\
\hline Reflection by a mirror & 22 & 23 \\
\hline Windows without louvers or shutters, light color curtains & 15 & 16 \\
\hline Windows without louvers or shutters, thin curtains & 11 & 12 \\
\hline Windows facing tree losing leaves in Fall & 10 & 11 \\
\hline Bedroom glass or slatted door & 10 & 11 \\
\hline Reflection from snow & 4 & 4 \\
\hline \multicolumn{3}{|l|}{ Sources of indoor artificial light reflecting into the bedroom } \\
\hline Low light flooding during all night from a corridor & 10 & 11 \\
\hline Light flooding from another room & 10 & 11 \\
\hline Bright light flooding from the corridor or the bathroom & 6 & 6 \\
\hline Standby light from smoke or fire detector & 5 & 5 \\
\hline Light from a heating device & 5 & 5 \\
\hline Night-light & 1 & 1 \\
\hline Charge indicator from electric razor & 1 & 1 \\
\hline \multicolumn{3}{|c|}{ Sources of outdoor artificial or natural light reflecting into the bedroom } \\
\hline Street light & 29 & 31 \\
\hline Light from the neighbor's front door & 13 & 14 \\
\hline Bright light from any source & 10 & 11 \\
\hline Street light beyond the block & 10 & 11 \\
\hline Street light within the same block & 9 & 10 \\
\hline Bright moon & 8 & 9 \\
\hline Light from close apartment or shop & 5 & 5 \\
\hline Traffic light & 5 & 5 \\
\hline Distant neon light & 5 & 5 \\
\hline
\end{tabular}


Table 3. Exact p-values of Wilcoxon tests (levels of evidence of each relationship between light pollution and each clinical sign of ovulation disorder)

\begin{tabular}{|c|c|c|c|c|c|}
\hline Menstrual cycle signs & Lux meter & $\begin{array}{l}\text { Artificial } \\
\text { light } \\
\text { in } \\
\text { bedroom }\end{array}$ & $\begin{array}{c}\text { Factors } \\
\text { increasing } \\
\text { light in } \\
\text { bedroom }\end{array}$ & $\begin{array}{c}\text { Indoor } \\
\text { artificial } \\
\text { light } \\
\text { reflecting } \\
\text { into bedroom }\end{array}$ & $\begin{array}{c}\text { Outdoor } \\
\text { artificial or } \\
\text { natural } \\
\text { light reflecting } \\
\text { into bedroom }\end{array}$ \\
\hline Menstrual flow -Mostly heavy flow & 0.728 & $0.038 *$ & $0.006^{*}$ & 0.246 & 0.198 \\
\hline No sustained basal body temperature shift or weak shift & 0.155 & 0.864 & 0.897 & $0.013^{*}$ & 0.881 \\
\hline Two days or more of spotting during mucus & 0.668 & 0.235 & $0.014^{*}$ & 0.595 & 0.265 \\
\hline A lot of mucus felt or seen during luteal phase & 0.319 & 0.234 & 0.383 & $0.018^{*}$ & 0.584 \\
\hline Minimal mucus. no peak type mucus & 0.549 & 0.675 & $0.023^{*}$ & 0.387 & 0.830 \\
\hline Less than 3 days of peak type mucus & 0.803 & 0.136 & 0.272 & 0.064 & 0.946 \\
\hline Early infertile days- No early infertile days & 0.246 & 0.611 & 0.728 & 0.728 & 0.064 \\
\hline Fertile mucus present after temperature rise & 0.175 & 0.754 & 0.474 & 0.070 & 0.673 \\
\hline Cervical mucus at the end of the menstrual flow & 0.084 & 0.732 & 0.613 & 0.098 & 0.704 \\
\hline Basal Body temperature shift- Erratic post-ovulatory readings & 0.280 & 0.479 & 0.562 & 0.086 & 0.895 \\
\hline Menstrual flow -Prolonged spotting after flow ends & 0.584 & 0.584 & 0.105 & 0.739 & 0.416 \\
\hline Short luteal phase (less than 10 days) & 0.296 & 0.830 & 0.113 & 0.216 & 0.645 \\
\hline Delayed BBT shift (19 days or more) & 0.987 & 0.969 & 0.389 & 0.119 & 0.997 \\
\hline Menstrual flow - Brown/blackish spotting & 0.584 & 0.416 & 0.141 & 0.964 & 0.319 \\
\hline More than two days of spotting during the luteal phase & 0.883 & 0.626 & 0.146 & 0.579 & 0.328 \\
\hline Bleeding/spotting for 5-6 days within the cycle before ovulation & 0.854 & 0.421 & 0.146 & 0.374 & 0.526 \\
\hline Temperature readings become weak from mid luteal to end of cycle & 0.158 & 0.579 & 0.842 & 0.947 & 0.211 \\
\hline Continuous dampness or wetness entire cycle & 0.235 & 0.960 & 0.298 & 0.557 & 0.632 \\
\hline Continuous fertile mucus entire cycle & 0.790 & 0.737 & 0.684 & 0.263 & 0.947 \\
\hline Menstrual flow of 7 days or more & 0.995 & 0.296 & 0.387 & 0.916 & 0.325 \\
\hline Cycle Length- 35 days or more & 0.673 & 0.328 & 0.626 & 0.673 & 0.883 \\
\hline Seven days or more of mucus & 0.329 & 0.358 & 0.516 & 0.969 & 0.420 \\
\hline
\end{tabular}

"Values $<0.05$ are in favor of a potential ability of the factor to predict the sign

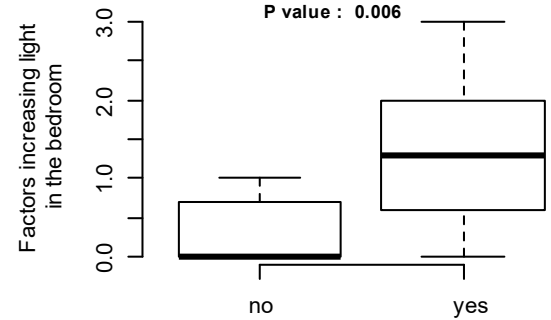

Menstrual flow -Mostly heavy flow

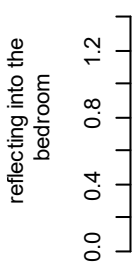

$P$ value : 0.01

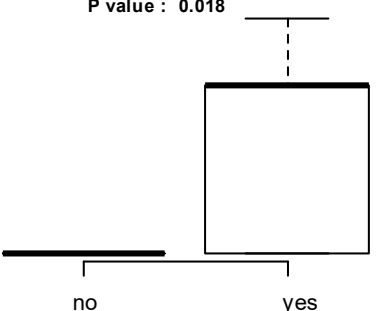

A lot of mucus felt or seen during lutea phase

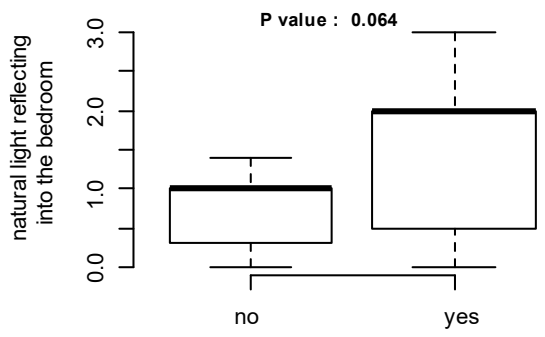

No early infertile days

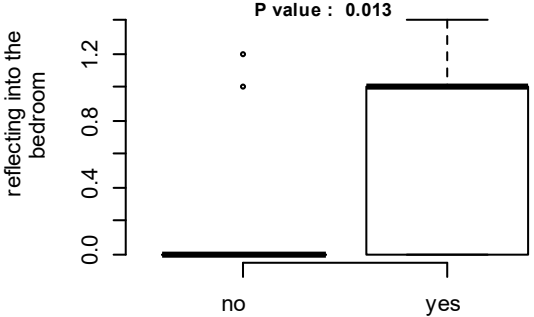

No sustained BBT shift or w eak shift

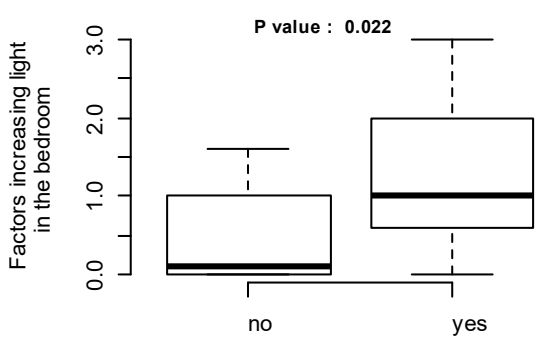

Minimal mucus, no peak type mucus

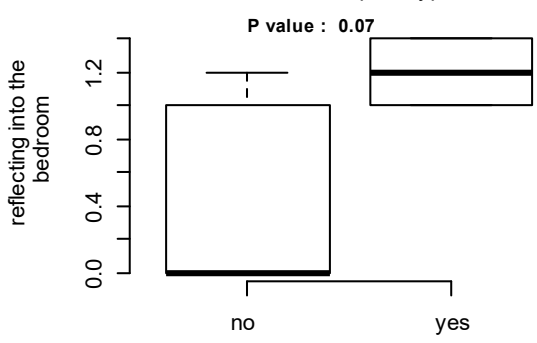

Fertile mucus present after temperature rise

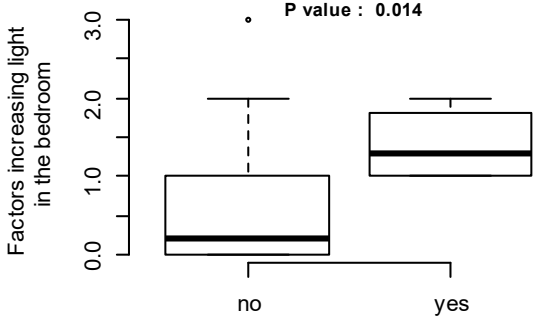

Tw o days or more of spotting during mucus

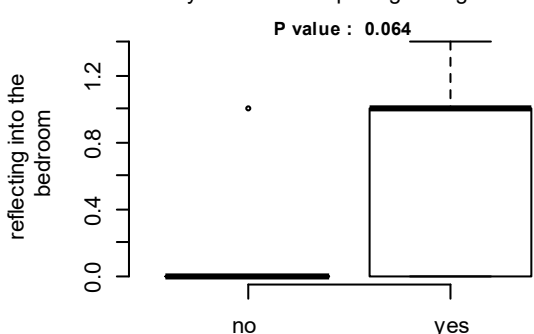

Less than 3 days of peak type mucus

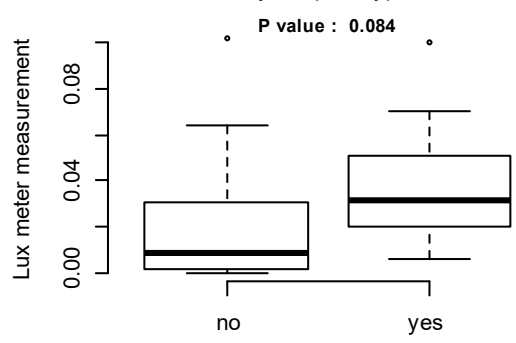

cervical mucus at the end of the menstrual flow, whereas fertile days $w$ ill beginn later

Figure 2. Boxplots illustrate the relationships between light pollution and clinical signs of ovulation disorder where Wilcoxon test p-value $<0.10$ 
pollution and each clinical sign of ovulation disorder. This table shows that $6 \mathrm{p}$-values were lower than 0.05 ; this is in favor of a potential ability of prediction of a clinical sign of ovulation disorder by the corresponding light pollution source.

Figure 2 shows the boxplots generated to illustrate the relationship between light pollution and each clinical sign of ovulation disorder in situations where Wilcoxon test $\mathrm{p}$-value is below 0.10 . These plots show that light pollution was higher in presence of some clinical signs of ovulation disorder; this is in favor of a possible prediction of clinical signs of ovulation disorder by light pollution. Nevertheless, the lowest of these p-values was 0.006; i.e., none reached the Bonferroni limit, which was 0.00045 . This calls to moderate the assertion of statistical significance of each relationship.

\section{Discussion}

The present study showed that nearly more than half of the menstrual cycles described by the participants presented at least mild abnormalities and that half of the measurements made by questionnaire or by lux meter showed a light pollution due to indoor or outdoor sources. The results allow concluding that signs of ovulation disorders may be predicted by light pollution.

The study found a high frequency of abnormalities in menstrual cycles (or ovulation disorders); this may be partly explained by a selection bias: women with such disorders would be more prone to participate. Nevertheless, several authors who studied natural cycles have described their great diversity in the general population [24,25]. A continuum from normal cycles to anovulatory cycles has been recently described by Blackwell et al. [26]. Moreover, the high frequency of abnormal cycles is regularly mentioned, especially in the presence of polycystic ovary syndrome [27].

Our sampling process was not devoted to quantify the prevalence of light pollution; the high frequency of light pollution observed here is not representative of a specific geographic area. The assessment of pollution sources was only destined to understand the participant environments and sleep conditions and help providing a list of sources of light pollution that may be contained or suppressed.

Furthermore, in this analysis, a lack of power was due to the small sample size which prevented reaching the Bonferroni limit. Actually, in such a study on 19 women, the Bonferroni limit is very low and has almost no chance of being reached.

Previous studies conducted among nurses have shown that working in shifts increases menstrual cycle irregularities and the occurrence of painful periods [28]. Women with more than 20 months of rotating shift work had higher risks of irregular cycles or atypical cycle lengths ( $<21$ days or $\geq 40$ days) [18]. Exposure to light at night might be one of the main causes of these ovulation disorders; it has been very recently considered as an "environmental endocrine disruptor" [29]. The results reported here might be a consequence of this phenomenon because light flooding into the bedroom was mentioned by two thirds of the women and was able to predict clinical signs of ovulation disorders. However, the impacts of exposure to light during shift work would be different from those of exposure to dim light during sleep [30].

\section{Conclusions}

Because deleterious health effects of dim light at night (versus total dark) have been observed in rodents [31,32], it seemed logical to check for a possible negative impact of dim light at night on women's menstrual cycles. The present results indicate a negative impact of light pollution of the bedroom on some characteristics of the menstrual cycle. Given the limited number of participants (thus, the lack of power), these indications call for conducting a randomized study to check whether a total suppression of light in the bedroom (versus dim light) would improve cycle characteristics. Such a study may open new therapeutic perspectives for some difficult cases of ovulation disorders.

\section{Funding}

This research received no specific grant from public, commercial, or not-for-profit sector. It was fully author funded.

\section{Declarations}

The authors declare they have no actual or potential competing financial interests.

\section{References}

1. Sharma R, Biedenharn KR, Fedor JM, Agarwal A (2013) Lifestyle factors and reproductive health: Taking control of your fertility. Reprod Biol Endocrinol 11: 66. [Crossref]

2. American college of obstetricians and gynecologists committee on gynecologic practice and practice committee (2014) Female age-related fertility decline. Committee opinion No. 589. Fertil Steril 101: 633-634.

3. Slama R, Bottagisi S, Solansky I, Lepeule J, Giorgis-Allemand L, et al. (2013) Shortterm impact of atmospheric pollution on fecundability. Epidemiology 24: 871-879. [Crossref]

4. Giorgis-Allemand L (2017) Atmospheric pollution and human reproduction. Neurons and cognition [q-bio.NC] dissertation. Genoble, France: Univ Grenoble Alpes.

5. Checa Vizcaíno MA, González-Comadran M, Jacquemin B (2016) Outdoor air pollution and human infertility: A systematic review. Fertil Steril 106: 897-904. [Crossref]

6. Sen A, Sellix MT (2016) The circadian timing system and environmental circadian disruption: From follicles to fertility. Endocrinology 157: 3366-3373. [Crossref]

7. Reiter RJ, Tamura H, Tan DX, Xu XY (2014) Melatonin and the circadian system Contributions to successful female reproduction. Fertil Steril 102: 321-328. [Crossref]

8. Lewy AJ, Wehr TA, Goodwin FK, Newsome DA, Markey SP (1980) Light suppresses melatonin secretion in humans. Science 210: 1267-1269. [Crossref]

9. Dumont M, Paquet J (2014) Progressive decrease of melatonin production over consecutive days of simulated night work. Chronobiol Int 31: 1231-1238. [Crossref]

10. Kozaki T, Kubokawa A, Taketomi R, Hatae K (2016) Light-induced melatonin suppression at night after exposure to different wavelength composition of morning light. Neurosci Lett 616: 1-4. [Crossref]

11. Gooley JJ, Chamberlain K, Smith KA, Khalsa SB, Rajaratnam SM, et al. (2010) Exposure to room light before bedtime suppresses melatonin onset and shortens melatonin duration in humans. J Clin Endocrinol Metab 96: E463-E472. [Crossref]

12. Kozaki T, Hidaka Y, Takakura JY, Kusano Y (2018) Suppression of salivary melatonin secretion under $100-\mathrm{Hz}$ flickering and non-flickering blue light. J Physiol Anthropol 37: 23. [Crossref]

13. Barron ML (2007) Light exposure, melatonin secretion, and menstrual cycle parameters: An integrative review. Biol Res Nurs 9: 49-69. [Crossref]

14. Davis S, Mirick DK, Stevens RG (2001) Night shift work, light at night, and risk of breast cancer. J Natl Cancer Inst 93: 1557-1562. [Crossref]

15. Baker FC, Driver HS (2007) Circadian rhythms, sleep, and the menstrual cycle. Sleep Med 8: 613-622. [Crossref]

16. Hatch MC, Figa-Talamanca I, Salerno S (1999) Work stress and menstrual patterns among American and Italian nurses. Scand J Work Environ Health 25: 144-150. [Crossref]

17. Su SB, Lu CW, Kao YY, Guo HR (2008) Effects of 12-hour rotating shifts on menstrua cycles of photoelectronic workers in Taiwan. Chronobiol Int 25: 237-248. [Crossref]

18. Lawson CC, Whelan EA, Lividoti Hibert EN, Spiegelman D, Schernhammer ES, et al. (2011) Rotating shift work and menstrual cycle characteristics. Epidemiology 22 305-312. [Crossref] 
19. Manser C (1996) Effects of lighting on the welfare of domestic poultry: A review. Anim Welf 5: 341-360.

20. DeFelice J, Kambic R, DeFelice R (2000) Light elimination therapy for the treatment of infertility: A pilot study. Paper presented at the science and research forum, American academy of natural family planning annual meeting, St Paul, MN.

21. DeFelice J, Kambic R, DeFelice R (2002) Light elimination therapy for the treatment of infertility: A pilot study. Paper presented at the Billings ovulation method of America meeting, Seattle, WA.

22. Vigil P, Blackwell LF, Cortés ME (2012) The importance of fertility awareness in the assessment of a woman's health - A review. Linacre Q 79: 426-450. [Crossref]

23. Hilgers TW, Stanford JB (1998) Creighton model NaProEducation technology for avoiding pregnancy. Use effectiveness. J Reprod Med 43: 495-502. [Crossref]

24. Alliende ME (2002) Mean versus individual hormonal profiles in the menstrual cycle. Fertil Steril 78: 90-95. [Crossref]

25. Abdulla SH, Bouchard TP, Leiva RA, Boyle P, Iwaz J, et al. (2018) Hormonal predictors of abnormal luteal phases in normally cycling women. Front Public Health 6: 144. [Crossref]
26. Blackwell LF, Vigil P, Cooke DG, d'Arcangues C, Brown JB (2013) Monitoring of ovarian activity by daily measurement of urinary excretion rates of oestrone glucuronide and pregnanediol glucuronide using the Ovarian Monitor, Part III: Variability of normal menstrual cycle profiles. Hum Reprod 28: 3306-3315. [Crossref]

27. Lizneva D, Suturina L, Walker W, Brakta S, Gavrilova-Jordan L, et al. (2016) Criteria prevalence, and phenotypes of polycystic ovary syndrome. Fertil Steril 106: 6-15. [Crossref]

28. Labyak S, Lava S, Turek F, Zee P (2002) Effects of shiftwork on sleep and menstrual function in nurses. Health Care Women Int 23: 703-714. [Crossref]

29. Russart KLG, Nelson RJ (2018) Light at night as an environmental endocrine disruptor Physiol Behav 190: 82-89. [Crossref]

30. O'Carroll DC, Warrant EJ (2017) Vision in dim light: Highlights and challenges. Philos Trans R Soc Lond B Biol Sci 372. [Crossref]

31. González MMC (2018) Dim light at night and constant darkness: Two frequently used lighting conditions that jeopardize the health and well-being of laboratory rodents. Front Neurol 9: 609. [Crossref]

32. Aubrecht TG, Jenkins R, Nelson RJ (2015) Dim light at night increases body mass of female mice. Chronobiol Int 32: 557-560. [Crossref]

Copyright: (C2019 Garmier-Billard M. This is an open-access article distributed under the terms of the Creative Commons Attribution License, which permits unrestricted use, distribution, and reproduction in any medium, provided the original author and source are credited. 